\title{
EFFECT OF X-RAYS ON THE MUTATION OF $t$-ALLELES IN THE MOUSE
}

\author{
MARY F. LYON \\ M.R.C. Radiobiological Research Unit, Harwell, Berkshire
}

\section{INTRODUCTION}

Received I8.ix.59

THE $t$-alleles are a long series of recessive alleles at locus $T$ of the house mouse, which show a combination of unusual properties. The dominant mutant alleles $T$ and $T^{h}$ produce a short-tailed mouse when heterozygous with wild-type and are lethal when homozygous. All $t$-alleles when in combination with $T$ produce a completely tailless mouse, and in combination with the wild-type allele a normal-tailed one. When homozygous some $t$-alleles are lethal and others are viable and result in a normal tail. Other properties found in some alleles include effects on male fertility, abnormal segregation ratios when the allele is carried in the male, and suppression of crossing-over between $T$ and nearby loci (Dunn, 1954). However, the property which is of interest here is the apparent high mutation rate to new $t$-alleles which is found in stocks carrying a $t$. For lethal $t$-alleles balanced lethal lines of genotype $T t \times T t$ can be formed, which breed true for taillessness. Dunn and Gluecksohn-Waelsch (1953) showed that in such lines $\mathrm{I}$ in about 500 offspring is an exceptional normaltailed animal. These normal-tailed exceptions carry a mutant $t$-allele, being heterozygotes for the original $t$-allele and the mutant. In a balanced lethal stock carrying $t^{1}$, I I normal tails were found in 3500 offspring and in a stock carrying $t^{0}, 4$ were found in 2000 young. The spontaneous mutation rate in male gametogenesis to recessive visible alleles at 7 loci studied by Russell, Russell and Kelly (1958) and by Carter, Lyon and Phillips (1958) was 25 out of 406,343 , i.e. an average rate for a single locus of about $0.8 \times 10^{-5}$. Hence the observed mutation rate of $t$-alleles is of the order of 200 times that expected for a single locus.

Since $t$-alleles have properties which, in the mouse, seem peculiar to them alone, they might seem of little interest in radiation genetics. However, Dunn (1955) has shown that they are very commonly present in wild populations. Of 18 wild populations investigated 12 contained a $t$-allele, and in these 12 populations 27 out of 47 individuals tested proved to be $+t$ heterozygotes. Hence, despite their peculiarities, $t$-alleles must be considered part of the " normal " genetic make-up of the mouse and should be included in any complete study of mouse radiation genetics.

The present work is a study of the effect of X-rays on the mutation rate of $t$-alleles with two points in view. First, it was hoped to test with 
the $t$-alleles the hypothesis that the frequency of radiation-induced mutation in the mouse is proportional to the spontaneous mutation rate. Secondly, if this hypothesis were supported, then radiationinduced mutation of $t$-alleles would occur with a relatively very high frequency and balanced lethal tailless lines might prove useful stocks for the study of induced mutation in the mouse.

The experiment has proved unsuccessful in its original purpose but the results have the interest of lending support to the suggestion put forward by Lyon and Phillips (I959) that "mutation" of $t$-alleles is in fact not mutation but crossing-over in an abnormal chromosome region.

\section{EXPERIMENTAL METHOD}

The lethal $t$-allele, $t^{6}$, which is not distinguishable from $t^{0}$ (Dunn and GluecksohnSchoenheimer, 1950) was used to form a balanced lethal line of genotype $T t f / t^{6}+\times$ $\tau t f / t^{6}+, t^{6}$ having been shown to suppress crossing-over between $T$ and the linked locus of tufted, $t f$, which affects hair growth (Lyon and Phillips, 1959)

Two-month-old males of genotype $T t f / t^{6}+$ were irradiated with a dose of either 2oor or 6oor of X-rays (250 kV, HVL I.2 mm. Gu; $10 \mathrm{~mA}$; 229r/min.) to the hind part of the body and subsequently mated.

The 6oor dose was chosen so that the results should be directly comparable with those of Russell, Russell and Kelly (1958). Males receiving this dose were placed with two females of similar genotype 2-3 months after irradiation and were left to breed continuously.

The 2oor dose was chosen as probably the highest dose that could be given without inducing a sterile period; it would thereby enable sperm irradiated at all stages of maturation to be studied, which was desirable in view of the possibility that there might be one particular stage of maturation at which the $t$-alleles were peculiarly sensitive. Males irradiated with $200 \mathrm{r}$ were placed with 3 pairs of females for 12 weeks. They were put with the first two females immediately after irradiation and left for one week, when they were moved to the next pair. Thereafter, they were moved on at weekly intervals, returning to the first two females after one week with the third pair, and so on. Contemporaneous control unirradiated males were left breeding continuously with two females.

The young sired by these males were classified for tail length and tufted fur. All non-mutant animals were tailless and non-tufted, $T t f / t^{6}+$; two types of exceptions were found: normal-tailed non-tufted and tailless tufted. All animals of both these exceptional types were kept and tested genetically for the presence of a mutant $t$-allele. The normal-tailed animals were expected to be of the genotype $t^{6} t^{m}$ where $t^{m}$ is a mutant allele ; the tailless tufted animals were apparent crossovers between $t^{6}$ and $t f$ and were tested to find whether mutation of the $t$-allele had accompanied crossing-over.

\section{RESULTS}

The results are shown in table $\mathrm{I}$. The numbers of animals classified for tail length and for tufted fur are shown separately since the totals are very different, as a result of death of young between the times of the two classifications. The data from the 2oor series have been subdivided into young sired in weeks $\mathrm{I}-5$, by sperm irradiated in maturation stages, weeks 6-7 by sperm irradiated perhaps in maturation stages and perhaps as spermatogonia, and weeks 8-I2 in which sperm were definitely irradiated as spermatogonia. Very few young were sired 
in weeks 6 and 7 after irradiation; this is in line with the findings of Bateman (1958).

All the exceptional animals were found to carry mutant alleles at the $t$-locus, except for the one normal-tailed animal in the control series which died when only a few days old. The mutant alleles have

TABLE I

Types of offspring found

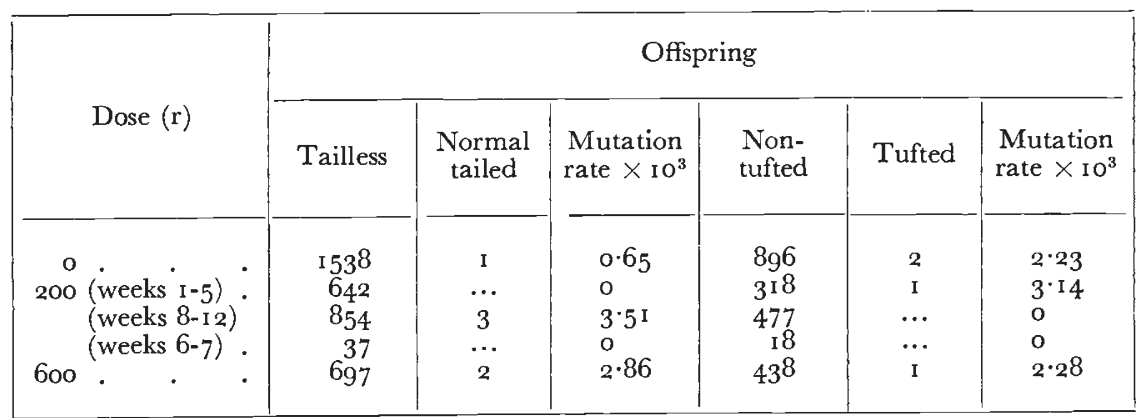

been given the symbols $t^{h 2}-t^{h 10}$. The four tailless tufted animals were all of the genotype $T t f \mid t^{h n} t f$, and of the normal-tailed animals four were of the type $t^{6}+\mid t^{h n} t f$, while the fifth carried a new kind of $t$-allele, not producing taillessness, and had the genotype $T t f \mid t^{h_{7}}+$.

\section{DISCUSSION}

\section{(i) Test of proportionality of induced and spontaneous} t-allele mutation

One aim of the experiment was to test the hypothesis that the frequency of radiation-induced mutation in the mouse is proportional to the spontaneous rate. To make this test it is necessary to work out

TABLE 2

Ratio of induced to spontaneous mutation in specific locus experiments

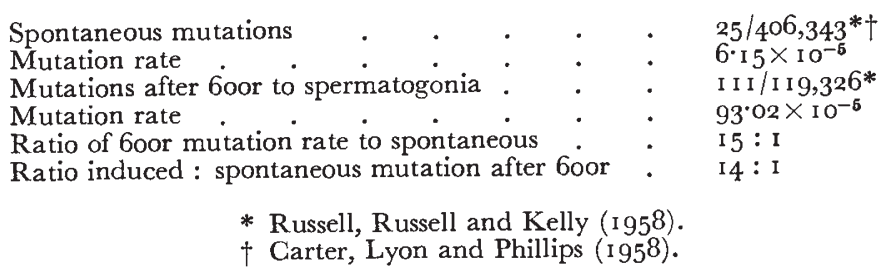

expected mutation rates for the present experiment on the basis that (a) the rate of induced $t$-allele mutation is proportional to the spontaneous mutation rate, and $(b)$ for the $200 \mathrm{r}$ dose, that the induced mutation rate increases linearly with dose. Table 2 shows that in the specific locus experiments previously mentioned the ratio of induced to 
spontaneous mutation after a dose of 6oor X-rays to spermatogonia was 14 to $\mathrm{I}$. In this experiment the spontaneous mutation observed was potentially occurring in both sexes, whereas in the irradiated series only the male parent was treated. Hence a proportional increase can only be expected in that part of the mutation attributable to the male. This part is not known but it will be assumed that half the spontaneous mutation occurred in the male, and therefore the expected mutation rates shown in table 3 have been arrived at by taking half the expected proportional increases. From the table it is clear that the increases in mutation rate of $t$-alleles after radiation treatment are

TABLE 3

Ratio of induced to spontaneous mutation for $\mathrm{t}$-alleles

\begin{tabular}{|c|c|c|c|c|c|c|}
\hline \multirow{2}{*}{ Dose (r) } & \multicolumn{3}{|c|}{ Mutation rate $\times 10^{3}$} & \multirow{2}{*}{$\begin{array}{l}\text { Ratio to } \\
\text { spontaneous }\end{array}$} & \multicolumn{2}{|c|}{$\begin{array}{c}\text { Ratio } \frac{\text { induced }}{\text { spontaneous }} \\
\text { mutation rate }\end{array}$} \\
\hline & $\begin{array}{l}\text { Tail } \\
\text { data }\end{array}$ & $\begin{array}{l}\text { Tufted } \\
\text { data }\end{array}$ & Total & & Observed & Expected \\
\hline 0. & 0.65 & $2 \cdot 23$ & $2 \cdot 88$ & $\ldots$ & $\ldots$ & $\ldots$ \\
\hline 200 (weeks 8-12). & $3 \cdot 5^{x}$ & o & $3 \cdot 5^{1}$ & $x \cdot 22$ & 0.22 & $2 \cdot 3$ \\
\hline 600 & $2 \cdot 86$ & $2 \cdot 28$ & $5 \cdot 14$ & $\therefore \cdot 79$ & 0.79 & $7 \cdot 0$ \\
\hline
\end{tabular}

much less than those expected, and that the data do not support the hypothesis of proportionality.

(ii) Is t-allele mutation a form of crossing-over?

This experiment having proved negative with regard to its original purpose its main interest lies in the light it throws on the nature of $t$-allele mutation.

The suggestion that $t$-allele mutation is in fact a form of crossingover arises from the association of this mutation with crossing-over between $t$ and nearby loci. The original $t$-allele in this experiment, $t^{6}$, was carried on the same chromosome as the wild-type allele of tufted, the genotype of all animals being $T t f / t^{6}+$. The mutants, with the exception of the unusual allele $t^{h r}$, were combined with $t f$, the animals being either $t^{6}+\mid t^{\text {hn }} t f$ or $T t f \mid t^{h n} t f$. Two explanations for this finding are possible. First, that the presence of a $t$-allele has induced a mutation in the homologous chromosome, in this case the $T$-tf-carrying chromosome; and second, that the apparent mutation of $t$-alleles is in fact the result of crossing-over in an abnormal chromosome region. Earlier work on crossing-over in mice heterozygous for $t$-alleles led to the same two explanations (Lyon and Phillips, 1959). Four cross-overs were found in the region of cross-oversuppression of $t^{6}$; three carried the complementary allele $T$ or + , 
according to the type of heterozygote used, and one carried a $t$-allele, which was found to be a mutant allele. The measured frequency of crossing-over in the T-tf region among the progeny of animals carrying $t^{6}$ was $2 / 526$. Thus, as a crossing-over hypothesis demands, the complementary cross-over types can be found and their frequency is of the same order of magnitude as that of the mutant $t$-alleles. Consequently, although neither explanation can be critically excluded, the hypothesis that $t$-allele mutation is in fact crossing-over in an abnormal chromosome region is favoured.

(iii) Is t-allele mutation affected at all by radiation ?

If $t$-allele mutation is not true mutation then the test of proportionality of induced and spontaneous mutation is not of general application to mutation in the mouse. On the other hand it would be of interest to test whether $t$-mutation is affected at all by radiation. To test this the data from all the irradiated animals have been pooled and compared with the control data (table 4). On the basis of tail classification only

TABLE 4

Comparison of control and irradiated series for a significance test

\begin{tabular}{|c|c|c|c|c|c|}
\hline & & Tailless & $\begin{array}{c}\text { Normal } \\
\text { tailed }\end{array}$ & $\begin{array}{l}\text { Non- } \\
\text { tufted }\end{array}$ & Tufted \\
\hline Control . & . & ${ }_{15} 3^{8}$ & I & 896 & 2 \\
\hline Irradiated & . & 2230 & 5 & $125^{1}$ & 2 \\
\hline
\end{tabular}

the observed mutation rate in the irradiated series is higher than in the controls, but when the probability of obtaining a difference as great or greater by chance was calculated using Fisher's (1954) exact method it was found to be as high as 0.22 . Moreover, considering tufted classification only, the mutation rate in the irradiated series is lower than that in the controls; therefore to combine the tail and tufted data would decrease the difference between irradiated and controls. Thus, if X-radiation increases the frequency of $t$-allele mutation at all in the male mouse then the increase is too small to be detected in an experiment of the scale of the present one.

\section{SUMMARY}

In balanced lethal tailless lines of the house mouse, of the genotype $T t \times T t$, mutation to new $t$-alleles occurs with a high frequency. The effect of X-rays on this mutation was investigated. $t$-allele mutation was not especially sensitive to radiation mutagenesis; in fact, if there was any increase at all in the $t$-allele mutation rate it was too small to be detected in an experiment of this scale. The genotypes of the 
mutants obtained favoured the hypothesis that $t$-allele mutation is in fact not true mutation but a form of crossing-over in an abnormal chromosome region.

Acknowledgments.-The author is grateful to Miss A. K. Fenn for technical assistance, and to Mr M. Corp and Miss E. M. Cosgrove for X-raying the mice.

\section{REFERENCES}

BATEMAN, A. J. 1958. Mutagenic sensitivity of maturing germ cells in the male mouse. Heredity, I2, 21 3-232.

CARTER, T. G., LYON, M. F., AND PHILliPS, R. J. S. 1958. Genetic hazards of ionising radiations. Nature, 182, 409 .

Dunn, L. C. 1954. The study of complex loci. Proc. IXth Internat. Congress Genetics. Caryologia, 6 Suppl., I 55-166.

DUNN, L. C. 1955. Widespread distribution of mutant alleles ( $t$-alleles) in populations of wild house mice. Nature, I76, 1275-1 276.

DUNN, L. C., AND GLUEGKSOHN-SCHOENHEIMER, s. I950. Repeated mutations in one area of a mouse chromosome. Proc. Nat. Acad. Sci., 36, 233-237.

DUNN, L. C., AND GLUEGKSOHN-WAELSCH, s. 1953. Genetic analysis of seven newly discovered mutant alleles at locus $\mathrm{T}$ in the house mouse. Genetics, 38, 26I-27I. FISHER, R. A. 1954. Statistical Methods for Research Workers. I 2th edition. Oliver and Boyd, Edinburgh.

LYON, M. F., AND PHILlIPS, R. J. S. 1959. Crossing-over in mice heterozygous for $t$-alleles. Heredity, 13, 23-32.

RUSSEll, W. L., RUSSELL, L. B., AND KELLy, E. M. 1958. Radiation dose rate and mutation frequency. Science, 128, I $546-1550$. 